$$
\text { "tmcs-ljajko" — 2010/11/14 — 22:24 — page } 277 \text { — \#1 }
$$

\title{
The hyperbola and Geogebra in high-school instruction
}

\author{
Eugen Ljajko, Milan Mihajlović and Zlatka Pavličić
}

Abstract. In this article the results of teaching/learning hyperbola and its characteristics in high-school using computers and GeoGebra are shown. Students involved in the research attend Engineering School "Nikola Tesla" in Leposavić, Serbia. The aim of the research was to define ways and volume of computer and GeoGebra usage in mathematics instruction in order to increase significantly students' mathematical knowledge and skills.

Key words and phrases: hyperbola, analytic geometry, GeoGebra, computer aided instruction.

ZDM Subject Classification: G70, D30.

\section{Introduction}

Analytic geometry is a field of great importance in secondary schools and engineering schools. Studying analytic geometry is considerably lightened with introduction of computers and appropriate software into mathematics lessons. We will show the way we studied hyperbola, its characteristics and relation to a (straight) line using computer and GeoGebra in third grades (which is 16-17 years old students) of engineering and secondary school classes of "Nikola Tesla" Engineering School in Leposavić, Serbia.

While studying hyperbola we used a textbook [5] and dynamic worksheetsapplets we made in order to present and explore relations and characteristics of hyperbola. It is important to point out that we taught all previous units of

Copyright (C) 2010 by University of Debrecen 
analytic geometry in the same way so the students were familiar with GeoGebra and its use in mathematics lessons.

\section{Equation of a hyperbola}

We define hyperbola as follows:

The locus of the set of points $M$ in a plain that have constant difference of distances between them and two fixed points $F_{1}$ and $F_{2}$ of the plain. (The difference of the distances is less than the distance between $F_{1}$ and $F_{2}$.)

If we take $\left|F_{1} F_{2}\right|=2 c$ and $M$ to be any point of the hyperbola then the following expression holds: ||$F_{1} M|-| F_{2} M||=2 c$. Points $F_{1}$ and $F_{2}$ are called foci of the hyperbola.

Usually, plenty of time in first lessons is wasted in attempts to sketch several points of the hyperbola or (even worse) a teacher is satisfied with formal learning of the given definition and an attempt (more or less successful) to derive the equation of the hyperbola out of the definition. Understanding the definition is of a crucial importance for understanding characteristics of the hyperbola and its relation to other objects. Therefore, we are of opinion that the definition should be derived in such a manner so it is easy to understand and remember, but still operational enough to derive characteristics of the hyperbola out of it. For this reason, instead of such a descriptive definition we used a genetic-descriptive one and it was put in a form of an applet- konship.ggb, Figure 1(a).

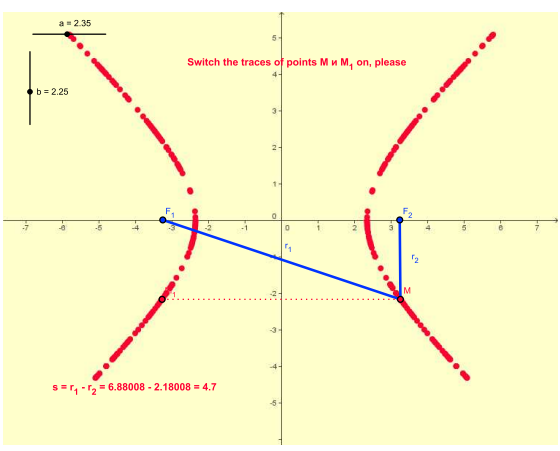

(a)

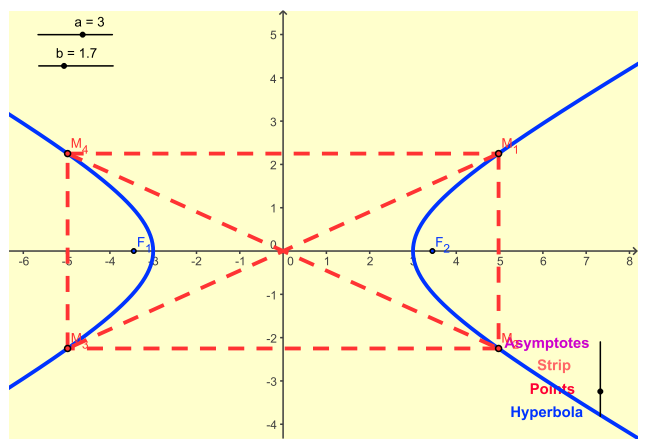

(b)

Figure 1
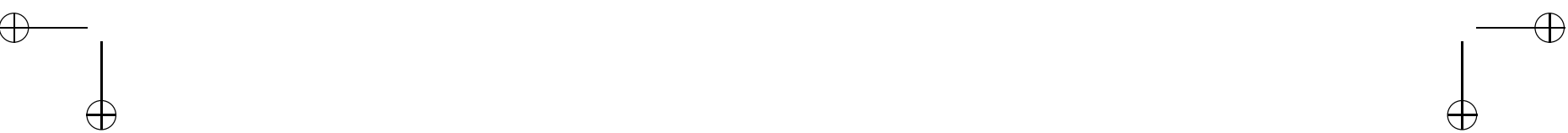


$$
\text { "tmcs-ljajko" — 2010/11/14 — 22:24 — page } 279 \text { — \#3 }
$$

In this way we created a dynamic process of building concept of hyperbola. Hence, visualization is not a mere illustration of the definition; it is rather its supplement that explains the genesis of the hyperbola.

Theorem. A point $M=(x, y)$ lies on hyperbola $\mathrm{h}$ if and only if its coordinates satisfy the following equation:

$$
\frac{x^{2}}{a^{2}}-\frac{y^{2}}{b^{2}}=1, \quad \text { where } \quad b=\sqrt{c^{2}-a^{2}}
$$

We state and prove this theorem in an "old fashioned" way, but we check the proof using applet hyperbola.ggb. We also present basic characteristics of hyperbola using the same applet. For instance, axis- and central symmetry of hyperbola can be viewed and proved adjusting vertical slider of the applet at position Points, Figure 1(b). One can check other characteristics of hyperbola using this applet in a similar way.

We combined computer and blackboard/notebook usage while explaining examples and solving problems. The following example we explained and solved using chalk and blackboard:

Example. Write down values $a$ and $b$ (major and minor half-axis), coordinates of foci and vertices as well as equations of asymptotes of the hyperbola $16 x^{2}-25 y^{2}=1$.

After solving the example on blackboard we made an appropriate applet using GeoGebra in order to check the results we obtained. This turned out to be very fruitful since we were able to create many related problems by simple varying the one we started with. This can be easily done by using a computer.

\section{Eccentricity and directrices of the hyperbola}

Following the way we did in the previous unit, first we show eccentricity and its influence on hyperbola using a GeoGebra applet-exdirh.ggb. After that, we define eccentricity to be the ratio of numbers $c$ and $a$ where $c$ is half of the distance between foci of the hyperbola and $a$ is major half-axis.

Directrices of the hyperbola and their characteristics as well as the theorem representing relation between the directrices and eccentricity are shown in the 


$$
\text { "tmcs-ljajko" — 2010/11/14 — 22:24 — page } 280 \text { — \#4 }
$$

same applet. Though we prove the theorem using chalk/blackboard, it is convenient to consider presenting it with the applet. Thus, we explained the theorem and even more, students were enabled to define the hyperbola to be the locus of the set of points that have a constant (and equal to the eccentricity) ratio of distances to a fixed point (focus) and to a fixed line (directrix), Figure 2(a).

The cases where values for axes are equal to zero which reflects in degeneration of the hyperbola into a (straight) line or two rays with vertices in the foci of the hyperbola are particularly interesting. These cases are clearly visible in our applet and they appear to be special cases of the original hyperbola when one adjusts values of the sliders $a=0$ and $b=0$. Teachers ought to pay attention to the way their students use GeoGebra while solving problems. As an example we present the following problem the students were given for homework:

Write down the equation of the hyperbola if its foci are real vertices of the ellipse (intersection points of $O x$ axis and the ellipse)

$$
\frac{x^{2}}{100}+\frac{y^{2}}{64}=1
$$

and its directrices pass through foci of the ellipse.

Though the students were free to choose the way they would solve the problem, majority of them decided to do it in a combined way, more or less relying on computers. Some of them used a computer as a drawing pad for sketches needed; others used it as a computational tool while another group used the computer and GeoGebra as a source of information needed to shape and solve the problem given to them. Anyway, this shows that most of the students tend to imitate ideas teacher sets forth in the class. Therefore, teachers should be highly careful when choosing methods of teaching the subject matter.

\section{The hyperbola and the straight line}

We determine relation of the hyperbola and a straight line by determining intersection points (if there is any) of the line $y=k x+n$ and hyperbola $\frac{x^{2}}{a^{2}}-\frac{y^{2}}{b^{2}}=1$ i.e. by solving an appropriate system of equations. GeoGebra offers a possibility to interpret the system in a geometric way. For that reason we decided to create an applet-prahip.ggb where we present relation of the hyperbola to a line, Figure 2(b). After a small experiment with the applet we were much easier to determine how the relation depends on the value of the expression $n^{2}+b^{2}-a^{2} k^{2}$ where $a, b, n$ 


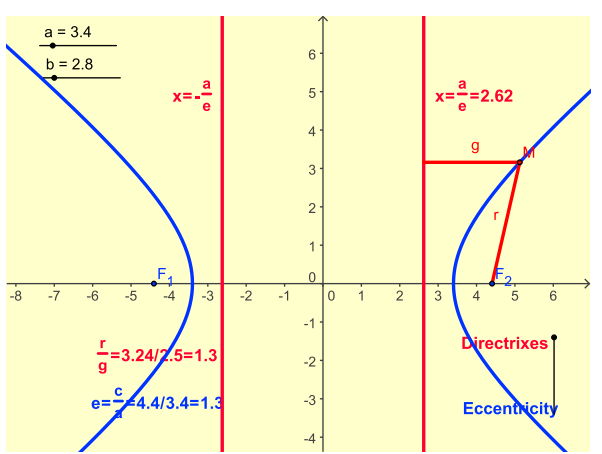

(a)

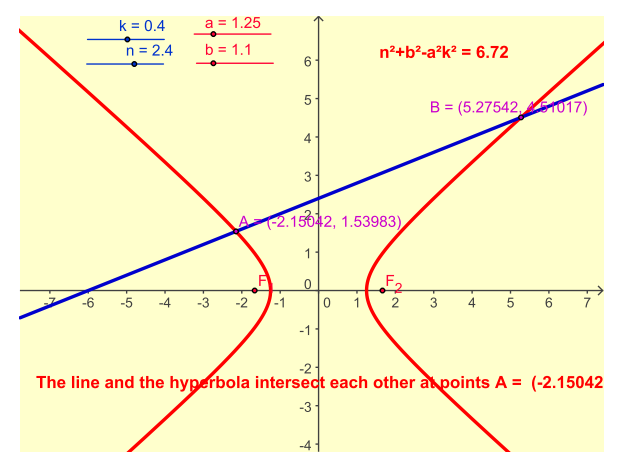

(b)

Figure 2

and $k$ are appropriate coefficients of the hyperbola and the line. We paid special attention to the case when the line is tangent to the hyperbola.

Although GeoGebra has a built-in tool that enables drawing tangents from a point to the hyperbola, we avoided its direct use while solving problems in order to foster initiative and creativity of students.

\section{Homework and students-teacher communication}

Students had freedom to choose a technology they would use in their homework. Thus, they could do it:

- In an "old fashioned way" - in a notebook and bring it to school,

- With a computer, using GeoGebra and bring it to school with a memory stick or

- Send it to the teacher using e-mail.

Majority of the students decided to use the third option, but there were still some of them that did it in the "old fashioned way". Disregarding the way students worked out their homework we did our best to treat equally their homework and be fair when evaluating it.

In addition to compulsory homework, teaching/learning mathematics in this way brought several innovations into the process. We encouraged students to communicate users with common sphere of interest at forum of the official site 
www.geogebra.org. There they met a wide community of students that do mathematics in a similar way and clarified possible imprecision they faced while learning mathematics. All the applets we used in lessons can be downloaded from the following internet page www.eugenljajko.info/hyperbola.html and they were available to students at any moment possible.

\section{Results}

We taught analytic geometry in 2008/09 and 2009/10 in the way we described here in secondary school classes ("G" group) and in the "old fashioned way" in electrical and mechanical engineering classes ("E" group). Grades average in general and in mathematics in first semesters are shown in Table 1.

\section{Table 1}

\begin{tabular}{|c|c|c|c|c|}
\hline Group & Year & Count & Gr. average general & Gr. average mathematics \\
\hline G & $2008 / 09$ & 22 & 2,94 & 3,05 \\
\hline E & $2008 / 09$ & 24 & 2,87 & 2,96 \\
\hline G & $2009 / 10$ & 21 & 2,91 & 2,95 \\
\hline E & $2009 / 10$ & 20 & 2,99 & 2,95 \\
\hline
\end{tabular}

One should mention that when forming groups, the "E" group was built up out of two separated sections and some of their students (two in 2008/09 and four in 2009/10) were not taken into consideration in order to balance the groups with regard to their grades average.

Lectures in both groups were based on the textbook [5]; the only difference was that the lectures in "E" group were held in the "old fashioned way". Here, sketching even simpler sketches consumed much longer time, comparing it with "G" group lectures. Besides, such sketches bear no dynamics. On the other hand, the applets we used in "G" group are dynamic and they quicken the teaching/learning process in terms of speed and efficiency of sketching and calculating. Thus, plenty of time can be used to discuss problems we dealt with. The applets also enable us to vary the initial problem situation and perceive wider aspects of the problem. This fosters students' creativity and strengthens their habit to look at the problem from different points of view.

After the material has been explained, in both groups we conducted tests that contained same questions/tasks. In 2008/09 both groups did the test in their notebooks, without computers. The next year both groups did the same test but 


$$
\text { "tmcs-ljajko" — 2010/11/14 — 22:24 — page } 283 \text { — \#7 }
$$

this time "G" group was allowed to use computers and build GeoGebra dynamic worksheets they needed. Results of the tests are shown in Table 2. Obviously, "G" group had better results. Values needed for estimation of statistical significance of the results are shown in Table 3 .

Table 2

\begin{tabular}{|c|c|c|c|c|}
\hline & \multicolumn{2}{|c|}{ G } & \multicolumn{2}{c|}{ E } \\
\cline { 2 - 5 } & Count & Grade average & Count & Grade average \\
\hline $2008 / 09$ & 22 & 3,18 & 24 & 2,96 \\
\hline $2009 / 10$ & 21 & 3,38 & 20 & 2,85 \\
\hline Total & 43 & 3,28 & 44 & 2,90 \\
\hline
\end{tabular}

At first we compared grades average of the groups we made joining together "G" group of 2008/09 with "G" group of 2009/10 and "E" group of 2008/09 with "E" group of 2009/10. Having in mind that $n_{1}=43$ and $n_{2}=44$ we used $z$ test. Since the computed $z$ value is $z=1.3529$ for $\alpha=0.05$ and $z \in$ $\left[-z_{\alpha / 2}, z_{\alpha / 2}\right]=[-1.96,1.96]$ we can accept the null hypothesis (The difference of the two means equals 0.0) i.e. the difference between the grades average is not statistically significant.

Table 3

\begin{tabular}{|c|c|c|c|c|}
\hline & \multicolumn{2}{|c|}{$\mathrm{G}$} & \multicolumn{2}{|c|}{$\mathrm{E}$} \\
\hline & $2008 / 09$ & $2009 / 10$ & $2008 / 09$ & $2009 / 10$ \\
\hline \multirow[t]{2}{*}{ Count } & 22 & 21 & 24 & 20 \\
\hline & \multicolumn{2}{|c|}{43} & \multicolumn{2}{|c|}{44} \\
\hline \multirow[t]{2}{*}{ Average } & 3,182 & 3,381 & 2,958 & 2,85 \\
\hline & \multicolumn{2}{|c|}{3,278} & \multicolumn{2}{|c|}{2,909} \\
\hline \multirow{2}{*}{$\begin{array}{l}\text { Standard } \\
\text { deviation }\end{array}$} & 1,259 & 1,322 & 1,3345 & 1,2258 \\
\hline & \multicolumn{2}{|c|}{1,278} & \multicolumn{2}{|c|}{1,273} \\
\hline \multirow{2}{*}{$\begin{array}{c}\text { Confidence } \\
\text { interval }\end{array}$} & $(2,610 ; 3,753)$ & $(2,758 ; 4,004)$ & $(2,382 ; 3,534)$ & $(2,261 ; 3,4389)$ \\
\hline & \multicolumn{2}{|c|}{$(2,881 ; 3,677)$} & \multicolumn{2}{|c|}{$(2,518 ; 3,301)$} \\
\hline
\end{tabular}

However, if we compare grades average of the groups in 2009/10 only, we come to a different conclusion. Having in mind that $n_{1}=21$ and $n_{2}=20$ we use $t$ test. Since the computed value is $t=2.5166$ for $\alpha=0.05$ and $t \notin$ $\left[-t_{\alpha / 2, n-1}, t_{\alpha / 2, n-1}\right]=[-2.021,2.021]$ we can reject the null hypothesis (The difference between the two means equals 0.0) in favor of the alternative one (The difference between the two means does not equal 0.0). This shows there is a 


$$
\text { "tmcs-ljajko" — 2010/11/14 — 22:24 — page } 284 \text { — \#8 }
$$

statistically significant difference between the means of the two samples at the 95\% confidence level.

Since the only difference with the previous statistical test was that "G" group used computers while doing the test, we draw conclusion that the way they did the test was the decisive aspect in rejecting the null hypothesis. However, having in mind small size of the groups we considered, one should be careful when generalizing results we obtained in the instruction process.

\section{Conclusion}

The way we used computers and GeoGebra in mathematics instruction process turned out to be very fruitful and interesting to students. Using computers in the process we make sketches and calculations faster and more precisely. In this way, students have more time to spend shaping, discussing and solving problems. Computers brought dynamics into instruction. Many objects can now be understood as processes rather than as static objects. This enables students to view different aspects of an object or mathematical problem. One can create, view and discuss many mathematical problems related to the initial one by a simple variation of the applet representing the initial problem. During the instruction and doing homework students often created their own GeoGebra dynamic worksheets. Thus, they became active participants of the teaching/learning process. Even more, every dynamic worksheet bears a personal imprint and it is through them and internet that students' work can be recognized worldwide. However, results of the tests show that a mere use of the computer and GeoGebra in lessons alone are not sufficient and their usage in testing as well would give better results. Attention should be paid to the way teachers use the computer and GeoGebra and combine them with the use of chalk/blackboard as it would reflect in students' work at large extend.

\section{References}

[1] L. Fahlberg-Stojanovska and V. Stojanovski, GeoGebra-Freedom to Explore and Learn, Teaching Mathematics and its Applications, March 2009.

[2] E. S. Haciomeroglu, B. Lingguo, R. C. Schoen and M. Hohenwarter, Learning to Develop Mathematics Lessons with GeoGebra, MSOR Connections 9, no. 2 (May-July 2009), 24-26. 


$$
\text { "tmcs-ljajko" — 2010/11/14 — 22:24 — page 285 — \#9 }
$$

[3] D. Herceg and E. Ljajko, Približno rešavanje jednačina pomoću računara, Nastava Matematike, Beograd LIII 1-2 (2008), 32-42 (in Serbian).

[4] M. Hohenwarter, J. Preiner and T. Yi, Incorporating GeoGebra into Teaching Mathematics at the College Level, Proceedings of ICTCM, Boston, 2007.

[5] J. D. Kečkić, Matematika sa zbirkom zadataka za treći razred srednje škole, Naučna knjiga, Beograd, ZUNS, Novi Sad (1990) (in Serbian).

EUGEN LJAJKO

DEPARTMENT OF MATHEMATICS AND INFORMATICS

FACULTY OF SCIENCES

KOSOVSKA MITROVICA

SERBIA

E-mail: eugenljajko@yahoo.com

MILAN MIHAJLOVIĆ and ZLATKA PAVLIČIĆ

ENGINEERING SCHOOL "NIKOLA TESLA"

LEPOSAVIĆ

SERBIA

E-mail: milanmih1980@yahoo.com

E-mail: zpavlicic@gmail.com

(Received April, 2010) 